\title{
Padronização de três ELISAs polivalentes com lipopolissacarídeos de cadeia longa dos sorotipos 1 e 5, 2, 3 e 7 ou 10 e 12 de Actinobacillus pleuropneumoniae
}

[Standardization of three polyvalent ELISA based on long chain lipopolysaccharides of serotypes 1 and 5, 2, 3 and 7, or 10 and 12 of Actinobacillus pleuropneumoniae]

\author{
S.S. Kuchiishi ${ }^{1}$, L.F.O.S. Carvalho ${ }^{1}$, I.A. Piffer ${ }^{2}$, J.D. Kich ${ }^{2}$, M.L.F. Ramenzoni ${ }^{2}$ \\ ${ }^{1}$ Faculdade de Ciências Agrárias e Veterinárias - UNESP \\ Via de Acesso Prof. Paulo Donato Castellane, km 5, \\ 14884-900 - Jaboticabal, SP \\ ${ }^{2}$ Embrapa Suínos e Aves - Concórdia, SC.
}

\begin{abstract}
RESUMO
Três ELISAs polivalentes baseados em lipopolissacarídeos de cadeia longa (LPS-CL) foram estabelecidos para detectar anticorpos para todos os sorotipos prevalentes de Actinobacillus pleuropneumoniae. Foram testadas amostras provenientes do banco de soros de suínos experimentalmente inoculados com todos os sorotipos de A. pleuropneumoniae. Os ELISAs foram sensíveis à detecção de anticorpos contra todos os LPS-CL. Foram observadas reações cruzadas no ELISA polivalente produzido com os sorotipos 1 e 5, com anti-soros específicos para os sorotipos 9 e 11, pois os sorotipos 1, 9 e 11 apresentaram antígenos somáticos comuns. No polivalente com os sorotipos 2,3 e 7, observaram-se reações com anti-soros dos sorotipos 4, 6 e 8, devido à presença de antígenos somáticos entre os sorotipos 3,6 e 8 e entre os sorotipos 4 e 7. Amostras de soros de animais infectados com Mycoplasma hyopneumoniae, Mycoplasma flocculare e Haemophilus parasuis, agentes que acometem o sistema respiratório dos suínos, não apresentaram reações cruzadas com os antígenos baseados em LPS-CL.
\end{abstract}

Palavras-chave: ELISA, pleuropneumonia, Actinobacillus pleuropneumoniae, sorologia, LPS

\begin{abstract}
Three polyvalent ELISA based on long chain lipopolysaccharides (LC-LPS) were established to detect all prevalent serotypes of Actinobacillus pleuropneumoniae. Samples from a serum bank of experimentally inoculated animals with all serotypes of A. pleuropneumoniae were tested. Antibodies specific to LC-LPS of each serotype were detected. Cross-reactions were observed in the polyvalent ELISA produced with serotypes 1 and 5, with specific antisera to serotypes 9 and 11 due to common somatic antigens presence in serotypes 1, 9, and 11. In the polyvalent with serotypes 2, 3 and 7 reactions were observed with antisera of serotypes 4, 6, and 8, due to the presence of somatic antigens in serotypes 3, 6, and 8 and serotypes 4 and 7. Experimentally infected animals with respiratory agents of swine Mycoplasma hyopneumoniae, Mycoplasma flocculare, and Haemophilus parasuis did not present cross-reactions with the antigens based on LC-LPS.
\end{abstract}

Keywords: ELISA, pleuropneumonia, Actinobacillus pleuropneumoniae, serology, LPS

\section{INTRODUÇ̃̃̃O}

A pleuropneumonia suína (PPS) é uma doença infecto-contagiosa causada por Actinobacillus pleuropneumoniae, que resulta em prejuízos com mortes, redução do desenvolvimento corporal dos animais, despesas com medicação e vacinação, serviços veterinários e condenações de carcaças ao abate, sendo essas decorrentes de aderências de pleura e nódulos de necrose pulmonar (Hunneman, 1986).

Recebido em 15 de outubro de 2007

Aceito em 28 de janeiro de 2008

suzanasatomi@yahoo.com.br

Apoio: FAPESP - Embrapa Suínos e Aves 
A transmissão ocorre por via aerógena e por contato direto entre os suínos mantidos na mesma baia ou em baias adjacentes, sendo que a principal fonte de infecção é a introdução de animais portadores sãos no rebanho (Morés et al., 1984). Fenwick e Henry (1994) citam que, no mundo, a maioria dos rebanhos suínos está infectada e apenas uma pequena fração dos suínos apresenta sinais clínicos.

As formas superaguda e aguda caracterizam-se por quadro de pleuropneumonia exsudativa, fibrino-hemorrágica e necrótica não-purulenta, enquanto a forma crônica se manifesta por aderências de pleura e pericárdio e focos de necrose pulmonares encapsulados (Shope, 1964; Higgins, 1982)

Baseados nas características dos polissacarídeos capsulares, foram descritos 15 sorotipos capsulares para o $A$. pleuropneumoniae (Gunnarson et al., 1977; Nielsen, 1988; Blackal et al., 2002).

Fenwick (1992), ao comparar diferentes testes sorológicos, concluiu que o ELISA e o teste da neutralização das citolisinas foram os melhores para a detecção de anticorpos, porém a eficiência do ELISA variou de acordo com o antígeno utilizado, sugerindo a padronização de técnicas e reagentes utilizados nas provas sorológicas para viabilizar programas de erradicação e controle da pleuropneumonia.

Dutra et al. (2000), ao padronizarem ELISAs monovalentes baseados em antígeno capsular purificado de $A$. pleuropneumoniae sorotipos 3, 5 e 7, os mais prevalentes no Brasil, verificaram especificidade de $100 \%$ e sensibilidade de 92,88 e $90 \%$, respectivamente. Concluíram que o teste é adequado para sorotipar a bactéria, visto que não ocorrem reações cruzadas com outros sorotipos nem com outros agentes causadores de problemas respiratórios.

Vários autores têm demonstrado as vantagens de se realizar testes polivalentes para os sorotipos mais prevalentes numa determinada região (Bunka et al., 1992; Fenwick, 1992; Kich et al., 1999).

No Brasil, Machado (1997) comparou ELISA com antígeno constituído pela fase aquosa da extração fenólica ou pelo lipolissacarídeo de cadeia longa polivalente (LPS-CL) e monovalente em soros de suínos experimentalmente inoculados. $\mathrm{O}$ antígeno polivalente obtido da fase aquosa da extração fenólica apresentou reação cruzada com os sorotipos 2 e 9, enquanto essa reação não foi observada no ELISA polivalente baseado em LPSCL. Todos os antígenos apresentaram especificidade de $100 \%$ e sensibilidade variável entre 88,3 e $98,3 \%$.

Kich et al. (1999) demonstraram que o ELISA polivalente, baseado em lipopolissacarídeos de cadeia longa com os sorotipos 3,5 e 7 do $A$. pleuropneumoniae, possui alta sensibilidade e, aparentemente, baixa especificidade. Portanto, tem características de teste de triagem, uma vez que detecta os sorotipos prevalentes no Brasil e sorotipos que possuem LPS-CL homólogos (3, 4, 5, 6, 7 e 8). O ELISA, entretanto, não identifica o estado portador em animais importados, que podem estar infectados por sorotipos comuns em sua origem, mas diferentes dos já detectados no país. Além disso, mesmo para animais nativos, como os testes não estão disponíveis, faltam informações necessárias para o transporte de animais de rebanho para rebanho, pois não são identificados os infectados com os sorotipos $1 \mathrm{e}$ 10 e outros menos freqüentes, já identificados no Brasil.

Considerando-se a importância do $A$. pleuropneumoniae para os núcleos de melhoramento genético e de multiplicação, importação e exportação de suínos, o objetivo deste trabalho foi estabelecer três ELISAs baseados em lipopolissacarídeos de cadeia longa (LPS-CL), capazes de detectar todos os sorotipos prevalentes de $A$. pleuropneumoniae.

\section{MATERIAL E MÉTODOS}

Foram produzidos antígenos compostos por lipopolissacarídeos de cadeias longas dos sorotipos 1, 2, 3, 5, 7 e 12 pela técnica de Dubreuil et al. (1992) e sorotipo 10 pela de Radacovici et al. (1995).

Foram padronizados três ELISAs polivalentes para a detecção de anticorpos denominados: polivalente A (poli A), contendo LPS-CL dos sorotipos 1 e 5 b, com reação cruzada aos sorotipos 9 e 11; polivalente B (poli B), sorotipos 2, 3 e 7, com reação cruzada aos sorotipos 4 e 8 ; e polivalente $C$

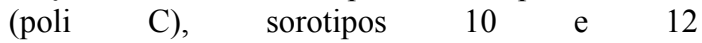
(Tab. 1). 
Tabela 1. Composição dos antígenos de cada teste polivalente e respectivos sorotipos detectados pelos testes em suínos

\begin{tabular}{ccc} 
Teste & Antígeno & Sorotipo detectado \\
\hline Polivalente A & 1 e 5 & $1,5,9$ e 11 \\
Polivalente B & 2,3 e 7 & $2,3,4,6,7$ e 8 \\
Polivalente C & 10 e 12 & 10 e 12 \\
\hline
\end{tabular}

Os soros experimentais obtidos de suínos livres de infecção por $A$. pleuropneumoniae foram oriundos de dois rebanhos negativos por investigação microbiológica e ELISA polivalente contendo os sorotipos 3,5 e 7 . Todos os soros foram submetidos a todos os ELISAs polivalentes e, após a leitura da mediana de três réplicas de cada um, foram calculados a média e o desvio-padrão da leitura do conjunto desses soros. Foram considerados negativos para fins de diagnóstico os soros que apresentaram um valor de densidade óptica (DO) menor que a média acrescida de quatro desvios-padrão para cada teste polivalente, determinando-se, assim, o ponto de corte. Esses soros foram misturados em volumes iguais para formar a alíquota de soros que constituíram o controle negativo.

Foram considerados positivos todos aqueles que apresentaram DOs mais altas que a média de todos os soros negativos acrescida de quatro desvios-padrão dos negativos. Esses soros testados foram provenientes de rebanhos com surto de PPS e de animais experimentalmente inoculados com A. pleuropneumoniae. Para os soros positivos, determinaram-se a média e o desvio-padrão das leituras dos testes para cada sorotipo, que foram organizados em três grupos: fracamente positivos, moderadamente positivos e fortemente positivos. Os soros de cada categoria também foram misturados em proporções iguais para constituírem os controles positivos do ELISA. Para cada teste, foram escolhidos os soros controles positivos do sorotipo que apresentaram a menor leitura de DO, quando testado com o antígeno polivalente.

Utilizaram-se soros negativos e positivos de todos os sorotipos utilizados como antígeno, com diferentes concentrações de antígeno e conjugado de forma multifatorial, para otimização do teste em um único teste de ELISA (Jacobson e Downing, 1991) conforme Fig. 1. Esses soros eram de animais provenientes de sistema SPF, animais experimentalmente inoculados ou naturalmente infectados.
Os testes polivalentes foram ajustados por meio de multifatorial, para que a leitura obtida com o controle positivo forte apresentasse DO igual a 1,0, com o ótimo da concentração de antígeno e conjugado ressaltando que, para cada nova partida de antígeno ou conjugado, deve-se realizar novo teste multifatorial.

As microplacas de poliestireno de 96 poços da marca Limbro/Titertec ${ }^{1}$ foram sensibilizadas com $100 \mu l$ do antígeno diluído em PBS pH 7,4 0,02 $\mathrm{M}$ acrescido de $0,03 \mathrm{M}$ de $\mathrm{NaCl}$ em cada poço e incubadas por aproximadamente 18 horas em câmara úmida à temperatura de $4^{\circ} \mathrm{C}$ e, a seguir, estocadas à temperatura de $-70^{\circ} \mathrm{C}$ para uso posterior.

Os soros foram testados em tréplica e diluídos a 1:400 com PBS Tween-20 com 1\% de albumina bovina. No dia do teste, as placas foram lavadas três vezes a cada intervalo de três minutos com PBS $\mathrm{pH} \quad 7,4$ contendo $0,05 \%$ de Tween-20. Após lavagem, colocaram-se 100 $\mu$ l do soro diluído 1:400 em cada poço; as placas foram incubadas a $37^{\circ} \mathrm{C}$ por 30 minutos e lavadas conforme descrito anteriormente. Colocaram-se $100 \mu$ d do conjugado peroxidase anti-IgG de suíno $^{2}$ diluído conforme teste multifatorial e incubou-se novamente a $37^{\circ} \mathrm{C}$ por 30 minutos, seguido de lavagem.

Solução contendo revelador [2,2 azino-bis (3 ethylbenzithazoline-6 sulphonic acid)] (ABTS), $4 \mathrm{mM}$ de peróxido de hidrogênio em tampão fosfato com $0,05 \mathrm{M}$ de citrato $(\mathrm{pH} 4,0)$ foi adicionada a cada poço $(100 \mu \mathrm{l})$. A reação enzimática, que ocorreu por 30 minutos em temperatura ambiente, foi interrompida com $50 \mu \mathrm{l}$ de ácido cítrico a $0,5 \mathrm{M}$. As placas foram agitadas por aproximadamente cinco segundos; posteriormente, realizou-se a leitura no espectrofotômetro marca Titertek Multiscan MCC/340 a 405nm de comprimento de onda. Os dados foram processados pelo programa Elisuave-Sistema de Leitura e Interpretação de ELISA desenvolvido na Embrapa Suínos e Aves.

${ }^{1}$ ICN Biomedicals, Inc Ohio, EUA.

${ }^{2}$ SIGMA-Aldrich Co, St Louis, EUA. 


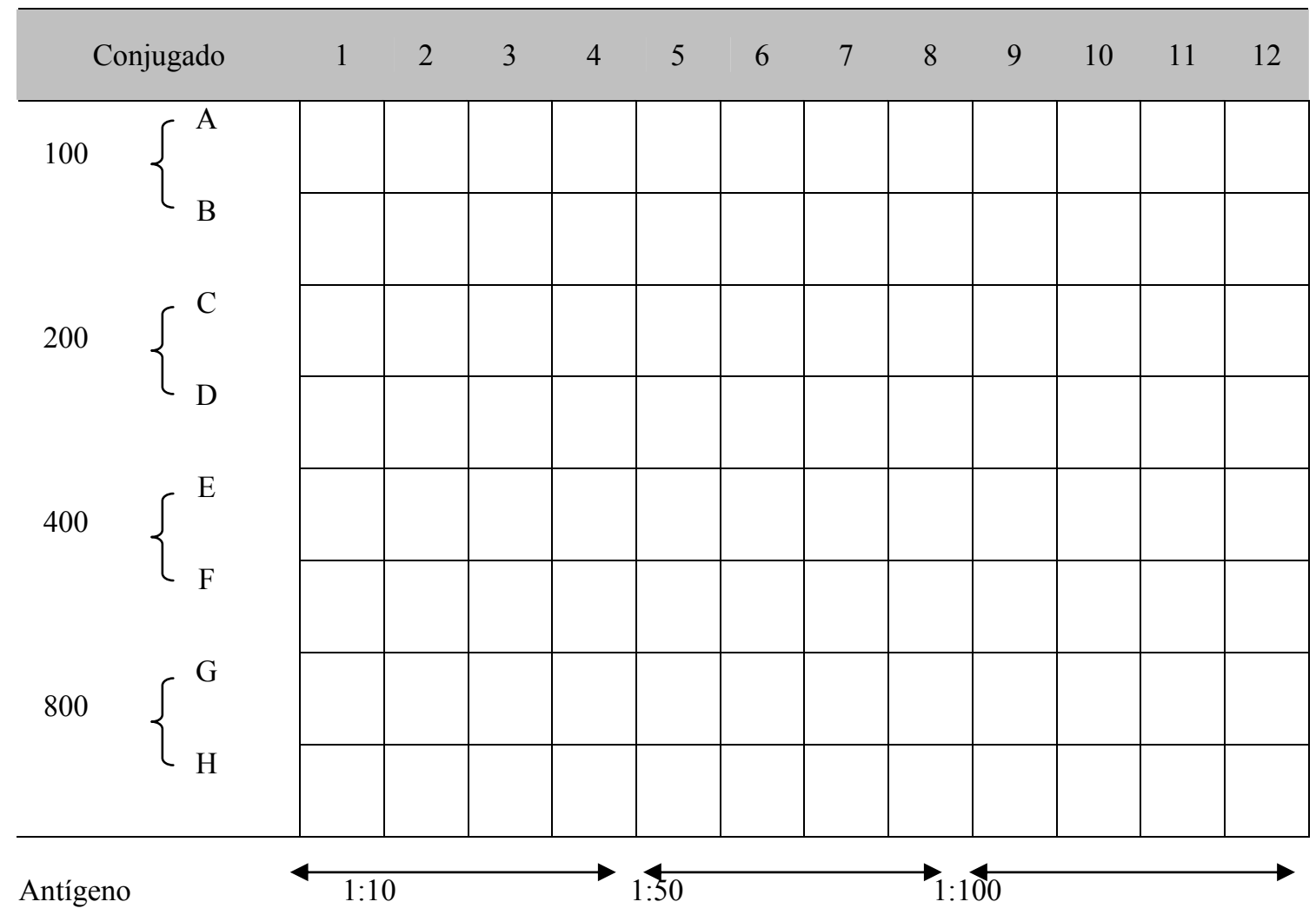

Colunas - 1, 5, 9: soro negativo $(1: 400) ; 2,6,10$ : soro fracamente positivo $(1: 400) ; 3,7,11$ :soro medianamente positivo (1:400); $4,8,12$ : soro fortemente positivo (1:400)

Figura 1. Diagrama de ELISA multifatorial para todos os ELISAs polivalentes em suínos, com conjugado anti-IgG de suíno peroxidase.

Foram testados soros de animais experimentalmente inoculados com todos os sorotipos de A. pleuropneumoniae, de animais mantidos em contato com os inoculados, animais controles negativo, sem contato com os anteriores, que foram colhidos em intervalos de uma semana, soros de animais infectados com suspensões vivas de Haemophilus parasuis, Mycoplasma hyopneumoniae e Mycoplasma flocculare, provenientes do banco de soros da Embrapa Suínos e Aves. A especificidade dos testes foi determinada com os soros dos animais controle negativo.

\section{RESULTADOS E DISCUSSÃO}

Para o ELISA polivalente A, o soro anti-sorotipo $5 \mathrm{~b}$ foi o que apresentou menor leitura de densidade óptica, estabelecendo-se como controle desse teste polivalente: para o poli $\mathrm{B}, \mathrm{o}$ sorotipo 7 e para o poli $\mathrm{C}$, o sorotipo 10 . Os valores dos pontos de corte de cada polivalente estão representados na Tab. 2, assim como suas respectivas médias e desvios-padrão.

$\mathrm{Na}$ Fig. 2 estão representadas as leituras do ELISA polivalente $\mathrm{B}$, que demonstram aumento linear das densidades ópticas dos soros utilizados como controles negativo e positivo do ELISA polivalente B. Os outros dois polivalentes (A e C) também apresentaram resultados semelhantes ao polivalente B. Para que esses valores sejam aceitos no programa Elisuave, devem mesmo estar dispostos linearmente, visto que este utiliza análise de regressão linear para ajuste dos valores médios da densidade óptica de três réplicas de cada soro testado, bem como de seus respectivos controles. Assim, o programa considera positivos os soros com DO ajustada superior à média dos controles negativos acrescida de quatro desvios-padrão. 
Tabela 2. Médias das densidades ópticas e respectivos desvios-padrão (DP) dos soros negativos, e pontos de corte de cada ELISA polivalente, em suínos

\begin{tabular}{cccc} 
Teste & $\begin{array}{c}\text { Média } \\
\pm \mathrm{DP}\end{array}$ & $4 \mathrm{DP}$ & $\begin{array}{c}\text { Ponto de corte } \\
\text { (Média + 4 DP) }\end{array}$ \\
\hline Polivalente A & $0,0998 \pm 0,0279$ & 0,1119 & 0,2118 \\
Polivalente B & $0,1079 \pm 0,0356$ & 0,1426 & 0,2505 \\
Polivalente C & $0,0735 \pm 0,0390$ & 0,1562 & 0,2297 \\
\hline
\end{tabular}

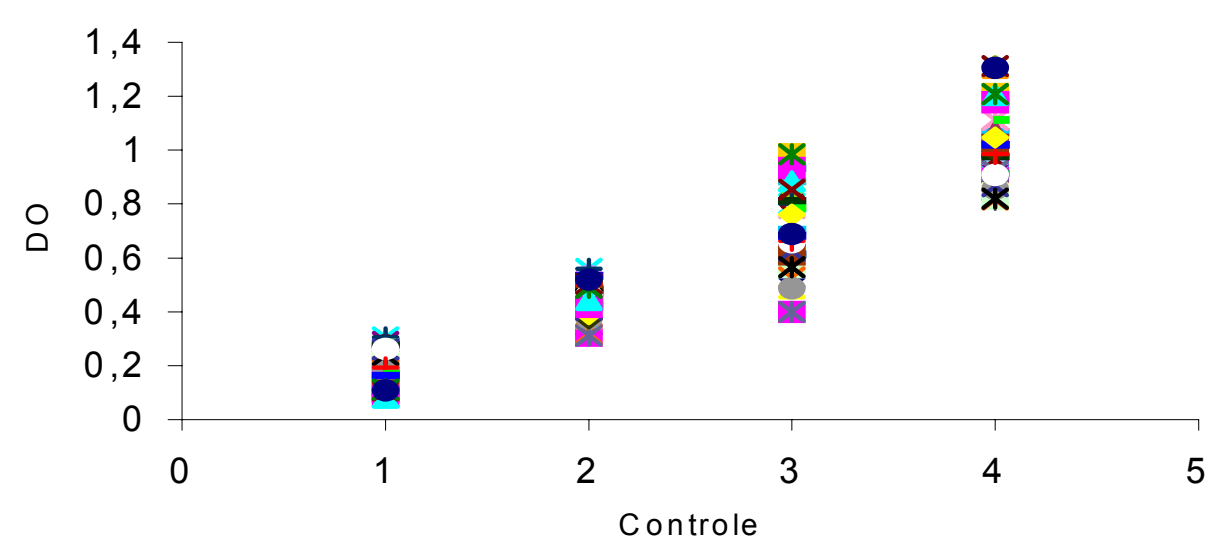

Figura 2. Valores de densidades ópticas (DO) dos soros controle detectadas pelo ELISA polivalente com antígeno LPS-CL de A. pleuropneumoniae sorotipos 2, 3 e 7 (poli B). (1) soros negativos; (2) soros fracamente positivos; (3) soros medianamente positivos; (4) soros fortemente positivos, em suínos.

Conforme previsto, foram observadas reações cruzadas no ELISA polivalente com os sorotipos 1 e 5, com anti-soros específicos para os sorotipos 9 e 11, por haver antígenos somáticos comuns entre os sorotipos 1,9 e 11 . No polivalente com os sorotipos $2, \quad 3$ e 7 observaram-se reações com anti-soros dos sorotipos 4, 6 e 8, por antígenos somáticos comuns entre os sorotipos 3, 6 e 8 e os sorotipos 4 e 7 (Beynon et al., 1992; Rodriguez Barbosa et al.,1995).

Os animais experimentalmente inoculados com o sorotipo 4 de A. pleuropneumoniae iniciaram soroconversão na primeira semana após inoculação, os inoculados com os sorotipos 1, 2, $3,5 b, 7,10$ ou 11 na segunda semana pósinfecção, os com o sorotipo 6 na terceira semana e os com o sorotipo 12 na quinta semana. Não se pode afirmar quando os animais inoculados com o sorotipo 9 iniciaram soroconversão, pois não foram testados soros da primeira e da segunda semana pós-infecção. Para o sorotipo 8 , foram testados apenas três soros, dois não reagentes e um soro com DO média de 1,054.

A dinâmica de soroconversão nos leitões experimentalmente inoculados e contatos e controles negativos de todos os sorotipos de $A$. pleuropneumoniae apresentaram perfis semelhantes ao da Fig. 3. Após a soroconversão, os títulos de anticorpos mantiveram-se reagentes até a última coleta, indicando que os testes foram suficientemente sensíveis e específicos e serão uma excelente ferramenta tanto para o diagnóstico quanto para utilizá-los na determinação de perfis sorológicos. Os animais controle negativo de todos os sorotipos apresentaram leitura de DO abaixo do valor do controle negativo.

Os ELISAs polivalentes A e B permitiram detecção de títulos de anticorpos mais altos que os dos controle positivo nos suínos experimentalmente infectados com os sorotipos $2,3,5 b$ e 7 . 


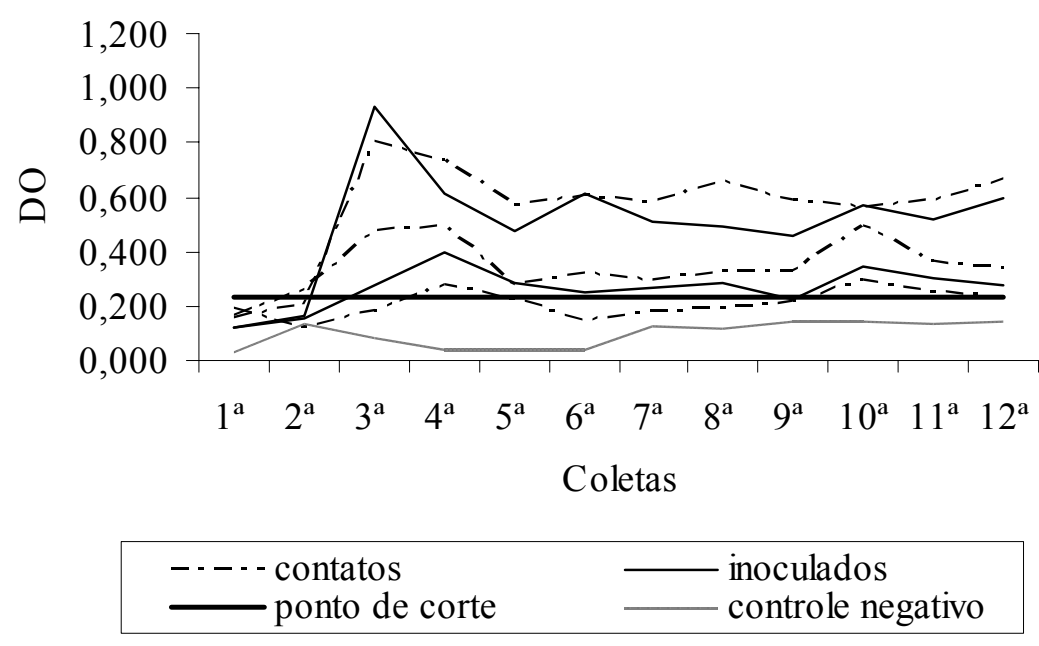

Figura 3. Valores de densidades ópticas (DO) detectadas pelo ELISA polivalente com antígeno LPS-CL de A. pleuropneumoniae sorotipos 2, 3 e 7, dos leitões infectados com o sorotipo 6 de $A$. pleuropneumoniae.

\begin{abstract}
Machado (1997) testou soros de animais infectados com Haemophilus parasuis, Mycoplasma hyopneumoniae, Mycoplasma flocculare e Actinobacillus suis, assim como de animais vacinados com Bordetella bronchiseptica e Pasteurella multocida, microrganismos que afetam o sistema respiratório dos suínos, e verificou reações negativas com os antígenos polivalentes. Neste trabalho foram testadas amostras de soros com anticorpos contra $M$. hyopneumoniae, $M$. flocculare e $H$. parasuis, que foram negativas aos três polivalentes.
\end{abstract}

Os testes polivalentes $\mathrm{A}, \mathrm{B}$ e $\mathrm{C}$ apresentaram sensibilidade de $88 \%, \quad 92 \%$ e $72 \%$, respectivamente, e todos eles especificidade de $100 \%$. A baixa sensibilidade do polivalente $\mathrm{C}$ foi devido à demora na soroconversão dos animais inoculados e contato com o sorotipo 12. Os testes apresentam alta sensibilidade e especificidade quando aplicados em animais experimentalmente inoculados, porém deve-se chamar atenção para a necessidade de sua validação no campo, em rebanhos positivos, onde haja isolamento ou PCR positivo para a bactéria, e em rebanhos negativos.

\section{CONCLUSÕES}

Os ELISAs polivalentes baseados em LPS-CL dos sorotipos 1 e $5 ; 2,3$ e 7; 10 e 12 de $A$. pleuropneumoniae são capazes de detectar anticorpos contra todos os sorotipos prevalentes de $A$. pleuropneumoniae no Brasil, em leitões experimentalmente inoculados e mantidos em contato, e podem ser adotados em programas de monitoria, desde que se realize sua validação no campo.

\section{AGRADECIMENTOS}

À Fundação de Amparo à Pesquisa do Estado de São Paulo - FAPESP e à Embrapa Suínos e Aves pelo apoio financeiro.

\section{REFERÊNCIAS BIBLIOGRÁFICAS}

BEYNON, L.M.; GRIFFITH, D.W.; RICHARDS, J.C. et al. Characterization of the lipopolysaccharide $\mathrm{O}$ antigens of Actinobacillus pleuropneumoniae serotypes 9 and 11 antigenic relationships among serotypes 9,11 and $1 . J$. Bacteriol., v.174, p.5324-5331, 1992. 
BLACKAL, P.J.; KLAASEN, H.L.B.M.; VAN DEN BOSCH, H. et al. Proposal of a new serovar of Actinobacillus pleuropneumoniae: serovar 15. Vet. Microbiol., v.84, p.47-52, 2002.

BUNKA, S.; FRANZ, B.; JECKSTADT, S.A. A mixed antigen ELISA for the detection of antibodies against Actinobacillus pleuropneumoniae serotypes 2, 3, 7 and 9. In: INTERNATIONAL PIG VETERINARY SOCIETY, 12., 1992, The Hague. Proceedings... The Hague: International Pig Veterinary Society, 1992. p.221.

DUBREUIL，J.D.; RADACOVICI，S. Purified lipopolysacharides of Actinobacillus pleuropneumoniae serotype 1: A readily obtaineble antigen for ELISA serodiagnosis of pig pleuropneumonia. In: INTERNATIONAL PIG VETERINARY SOCIETY, 12., 1992, The Hague. Proceedings... The Hague: International Pig Veterinary Society, 1992. p.222.

DUTRA, V.; PIFFER, I.A.; VARGAS, A.C. et al. Padronização do teste ELISA baseado em antígeno capsular purificado dos sorotipos 3,5 e 7 de Actinobacillus pleuropneumoniae. In: CONGRESSO BRASILEIRO DE VETERINÁRIOS ESPECIALISTAS EM SUÍNOS, 9., 1999, Belo Horizonte. Anais... Belo Horizonte: 1999. p.157-158.

FENWICK, B. Critical comparison of the serologic tests used to diagnose porcine pleuropneumonia. In: INTERNATIONAL PIG VETERINARY SOCIETY, 12., 1992, The Hague. Proceedings... The Hague: International Pig Veterinary Society, 1992. p.219.

FENWICK, B.; HENRY, S. Porcine pleuropneumonia. J. Am. Vet. Med. Assoc., v.204, p.1334-1340, 1994.

GUNNARSON, A.; BIBERSTEIN, E.I.; HURVELL, B. Serologic studies on porcine strains of Haemophilus parahaemolyticus (peluropneumoniae). Agglutination reactions. Am. J. Vet. Res., v.38, p.1111-1114, 1977.

HIGGINS, R. 1- La pleuropneumonie porcine à Haemophilus pleuropneumoniae. Med. Vet. Du Quebec, v.12, p.33-39, 1982.

HUNNEMAN, W.A. Incidence, economic effects, and control of Haemophilus pleuropneumoniae infections in pigs. Vet. Q.., v.8, p.83-87, 1986.

JACOBSON, R.H.; DOWNING, D.R. Kela aquisition, management and analysis of ELISA data. College of Veterinary Medicine; Diagnostic Laboratory. Ithaca: Cornell University, 1991. p.71.

KICH, J.D.; PIFFER, I.A.; GUIDONI, A.L. et al. Utilização de um teste de ELISA polivalente para a detceção de anticorpos contra Actinobacillus pleuropneumoniae. Arq. Bras. Med. Vet. Zootec., v.51, p.409-414, 1999.

MACHADO, H.G. Avaliação de testes de ELISA para o diagnóstico de infecções provocadas pelos sorotipos 3, 5 e 7 de Actinobacillus pleuropneumoniae em suínos. 1997. 90f. Dissertação (Mestrado) Universidade Federal de Pelotas, Pelotas, RS.

MORÉS, N.; SOUZA, J.C.A.; NOGUEIRA, R.H.G. Estudo experimental a pleuropneumonia suína causada por Haemophilus pleuropneumoniae (Hpp). Patogenicidade e evolução das lesões anatomo-patológicas. Arq. Bras. Med. Vet. Zoot., v.36, p.679-693, 1984.

NIELSEN, R. Seroepidemiology of Actinobacillus pleuropneumoniae. Can. Vet. J., v.29, p.580-582, 1988.

RADACOVICI, S.; GOTTSCHALK, M.; DUBREUIL, J.D. Recovery of long-chain lipopolysaccharides from liquid culture of Actinobacillus pleuropneumoniae (serotype 5) for ELISA serodignosis. Vet. Res., v.26, p.63-67, 1995.

RODRIGUEZ BARBOSA, J.I.; GUTIERREZ MARTÍN, C.B.; TASCON, R.I. et al. Evidence obtained with monoclonal antibodies that $\mathrm{O}$ antigen is the major antigen responsible for the cross-reactivities between serotypes 4 and 7 of Actinobacillus

(Haemophilus) pleuropneumoniae. Clin. Diag. Lab. Immunol., v.2, p.563-568, 1995.

SHOPE, R.E. Porcine contagious pleuropneumonia. 1. Experimental transmission, etiology, and pathology. J. Exp. Med., v.119, p.357-368, 1964. 